\section{Influence of Impurities on the Laser Induced Breakdown in Liquid $\mathrm{He}^{4}$}

\section{S. HunkLinger and P. Leiderer}

\author{
Physik Department E 10 der Technischen Universität \\ München
}

(Z. Naturforsch. 26 a, 587-588 [1971]; received 15 December 1970)

\section{Dedicated to Professor Dr. H. Maier-Leibnitz on his 60 th birthday}

The threshold power for laser induced breakdown in liquid $\mathrm{He}^{4}$ has been investigated above and below the $\lambda$-transition. The results secm to indicale that the threshold power is mainly determined by the impurity content of the liquid.

Recent experiments ${ }^{1-4}$ on lascr induced breakdown in compressed helium gas and in liquid helium suggest that optical breakdown is caused by an electronic avalanche mechanism ${ }^{5}$. According to this mechanism the threshold power for optical breakdown should increase with decrcasing electronic scatlering rate, or with atomic density since clectrons are mainly scattered by atoms. This close relationship between the threshold power and the atomic density has indeed becn observed both in helium gas ${ }^{1-3}$ and in liquid helium from $4.2^{\circ} \mathrm{K}$ to $2.2^{\circ} \mathrm{K}^{3}, 4$.

At lower temperatures, however, Winterling, HeINICKE and DRANSFELD ${ }^{4}$ observed a strong temperature variation of the threshold power, which increascd by one order of magnitude on cooling from $T_{\text {, }}$ to $1.5^{\circ} \mathrm{K}$, although the atomic density remains almost constant in this temperature interval.

In this communication we present evidence that this anomalous temperature dependence is not caused by a temperature dependent clectronic scattering ratc as suggested previously 4 , but by the impurity content of the liquid.

\section{The Role of Initial Electrons}

Abrikosova and Bochikovi ${ }^{3}$ as well as WinterLING and HEINICKE ${ }^{7}$ have observed an interesting lime dependence of the threshold power: The initial optical breakdown required the highest available laser power, while subsequent breakdowns a few minutes later could be produced by a power which was about one order of magnitude smaller. This reduction only disappeared if the lime interval between pulses was larger than 30 minules.

1 R. G. Meyerand and A. F. Maught, Phys. Rev. Lelters 11, 4.01 [1963].

2 D. H. Grll and A. A. Dougal, Phys. Rev. Letters 15, $845[1965]$.

3 I. I. Abrikosova and O. M. Bochrova, Zh ETF Pis. Red. 9, 285 [1969]. (English transl.: Sov. Phys. JFTP l.etters 9, 167 [1969].)

4 G. Wintering, W. Heinicke, and K. Dransfeld, Phys. Rev. 185, 285 ¡1969!.

: Ya B. Zel'Dovicir and YU P. Raizer, J. Fxpil. Theoret. Phys. (USSR) 47, 1150 [1964]. (English transl.: Sov. Phys. JETP 20, 772 [1965].
Theoretically, optical breakdown in pure helium can only occur at moderate threshold powers if there is at least one free electron in the focal volume ${ }^{5}$ of the liquid when the laser pulse is arriving. Therefore the question arises whether the relatively high threshold power observed for the first breakdown is simply caused by the lack of an initial electron, and whether the electrons - left over from the first breakdown are responsible for igniting the subsecuent brcakdown at a much lower threshold power.

In order to check this assumption we injected electrons from a hot cathode ${ }^{8}$ into the liquid sweeping them into the focal volume by an electric field $(50 \mathrm{~V} / \mathrm{cm})$. From the measured current density $\left(2 \cdot 1.0^{-11} \mathrm{~A} / \mathrm{cm}^{2}\right)$ and the known electronic mobility ${ }^{9}$ the number of electrons in the focal volume was estimated to be at least $10^{3}$. This high density of electrons (6 orders of magnitude higher than the natural background ${ }^{10}$ ) produced no observable influence on the threshold power neither for the first nor for subsequent pulses. - Winterling, HEINICKE and Dransfeld ${ }^{4}$ reached essentially the same conclusion from their experiments: By a dc electric field they swept away all charge carriers out of the focal volume. This removal of electrons prior to inducing breakdown had again no influence on the observed threshold power.

\section{The Role of Impurities}

From the above observations one can safely conclude that a considerably higher density of free electrons must be necessary for the production of breakdown. Presumably impurities alone, having a much lower ionisation energy than helium atoms, produce the first copious supply of electrons when the laser pulse arrives.

If no special precautions are taken to purify liquid helium, it may have an impurity content of one part per million or more, not only of $\mathrm{He}^{3}$ but also of microcrystallites of air and other materials which can be easily ionized in the initial phases of each laser pulse. If the number of fice carriers generated this way inside the focal volume exceeds about $10^{\circ}$ the threshold power for optical breakdown is expected to decrease noticeably ${ }^{5}$.

Since these foreign materials have mostly a density: higher than that of the liquid, they are able to sediment out, only rather slowly in He I, but relatively fast in superfluid Yle II ${ }^{11}$.

6 M. Silver, J. P. Hernandez, and D. G. OnN, Phys. Rev. AI, 1268 [1970].

7 G. WINTERLING and W. HLiNICKE, private communication.

${ }^{8}$ G. E. Srangler and F. L. Ilereford, Phys. Rev. Letters 20, 1229 [1.968].

9 K. W. SchWarz and R. W. Stark, Phys. Rev. Letters 22, $1278[1969]$.

10 C. Blank and M. H. EDmards, Phys. Rev. 119, 50 [1960].

11 P. Savich and A. I. Shal'nikov, J. Phyuics 10, 299 [1946]. 
If the breakdown is indeed promoted by sedimenting impurities one would except the threshold power to increase in time if the liquid is kept in the superfluid state:

1) When the liquid was maintained at $1.9^{\circ} \mathrm{K}$ for 30 minutes we observed an increase of the threshold power by one order of magnitude.

2) At the same temperature the threshold power decreased again by similar amount if the sedi- mentation of the impurities was prevented, for example, by simply stirring the liquid mechanically. All these observations lead to the conclusion that the presence of impurities in liquid helium plays a very important role in the observed process of optical breakdown.

The authors are greatly indebted to Prof. K. DRansfeld for many stimulating discussions. 